\title{
Rapid and high capacity adsorption of heavy metals by Fe3O4/montmorillonite nanocomposite using response surface methodology: preparation, characterization, optimization, equilibrium isotherms, and adsorption kinetics study
}

\begin{abstract}
Fe3O4/montmorillonite nanocomposite (Fe3O4/MMT NC) was synthesized for removal of $\mathrm{Pb} 2+, \mathrm{Cu} 2+$ and $\mathrm{Ni} 2+$ ions from aqueous systems. The nanoadsorbent was characterized by $\mathrm{X}$-ray diffraction and transmission electron microscopy and mean diameter of magnetic nanoparticles was about $8.24 \mathrm{~nm}$. The experiments were designed by response surface methodology and quadratic model was used to prediction of the variables. The adsorption parameters of adsorbent dosage, removal time, and initial heavy metal ions concentration were used as the independent variables and their effects were investigated on the heavy metal ions removal. Variance analysis was utilized to judge the adequacy of the chosen models. Optimum conditions with initial heavy metal ions concentration of 510.16, 182.94, and $111.90 \mathrm{mg} / \mathrm{L}, 120 \mathrm{~s}$ of removal time and $0.06 \mathrm{~g} / 0.025 \mathrm{~L}, 0.08 \mathrm{~g} / 0.025 \mathrm{~L}$, and $0.08 \mathrm{~g} / 0.025 \mathrm{~L}$ of adsorbent amount were given $89.72 \%, 94.89 \%$, and $76.15 \%$ of removal efficiency $\mathrm{Pb} 2+$, $\mathrm{Cu} 2+$ and $\mathrm{Ni2}+$ ions, respectively. Prediction of models was in good agreement with experimental results and Fe3O4/MMT NC was found successful in removing heavy metals from their aqueous solutions.
\end{abstract}

Keyword: Heavy metals; Fe3O4/montmorillonite nanocomposites; Adsorption; Response surface methodology; Adsorption kinetics 